\title{
Sleep behavior changes in quarantine during the COVID-19: Subject Review
}

\author{
${ }^{(1)}$ Ahmed A.Hussein Al-Jumaily, ${ }^{(2)}$ Nasir Muwfaq Younis, ${ }^{(3)}$ Mahmoud Mohammed Ahmed \\ (1) Instructor,. C H N, University of Mosul/College of Nursing" \\ (2) Assist.Prof,. C H N , University of Mosul/ College of Nursing" \\ (3)Instructor. C H N, , University of Mosul/ College of Nursing" \\ DOI: 10.29322/IJSRP.11.02.2021.p11058 \\ http://dx.doi.org/10.29322/IJSRP.11.02.2021.p11058
}

\begin{abstract}
Most citizens are doing less in terms of social contacts in the new international condition of house arrest due to the "COVID-19 outbreak". This can have an adverse impact on your mental and physical health. Deep changes in sleep behaviour have been brought on by the COVID-19 pandemic. This may not only raise the levels of everyday stress, but also interrupt sleep. Pertinently, sleep disruption may have direct effects on the everyday functioning of the next day due to the essential role that sleep plays in daily control. Although contacts are required to recognize health effects that can result from these altered sleep behavior, proposed improvements in health habits must also be investigated. Media studies have documented significant changes in sleep activity that could have resulting negative impacts. The complex interactions between health habits and the potential improvements in these found extremely from anti-pandemic interventions and what will be understood about the behavior of changing sleep, The consequences of the current home confinement situation, that could disrupt sleep, but also those that can increase the performance of sleep. There are suggested changes to psychotherapy. Handling sleep disorders as effectively as possible during home detention will alleviate tension and potentially avoid social relationship conflicts. Finally, the call for further research efforts to resolve the brief \& medium effects of improvements in sleep behavior is also highlighted.
\end{abstract}

Index Terms- Sleep, Behavior, COVID-19

\section{INTRODUCTION}

$\mathrm{I}^{\mathrm{t}}$ is suspected that the latest "COVID-19 outbreak" occurred in Dec- 2019 in Wuhan, China. The virus has spread exponentially since then, upwards of 196 countries and territories worldwide are now impacted. A global pandemic has now been declared by the "World Health Organization (WHO) and a variety of steps have been introduced to mitigate the spread of the virus. Most of these include social distancing, self-isolation and quarantine of those who have developed or likely contracted COVID-19" (1,2) .In homeostasis, energy metabolism, and cognitive function, "sleep is a physiological and behavioral condition that plays an important role" ${ }^{(3,4,5)}$. Most biological processes ${ }^{(6)}$, are coordinated by circadian rhythms, requiring intrinsic and endogenous clocks $^{(7) " R e g u l a t i n g ~ t h e ~ r h y t h m ~ o f ~ b i o l o g i c a l ~ m e c h a n i s m s ~ s u c h ~ a s ~}$ heart rate, gastrointestinal motility" ,hormone levels, metabolism of macronutrients, metabolic rate of energy ${ }^{(8)}$ and activities of the gastrointestinal system ${ }^{(9,10)}$."The population has been subjected to a prolonged period of social exclusion, also called self-quarantine" (11), since the onset of the pandemic . Quarantine allows individuals to remain at home ${ }^{(12)}$, modify their lifestyles ${ }^{(13)}$, and allow citizens to work at home, which is a source of stress, given that they do not have a vaccination and can only be treated symptomatically ${ }^{(14)}$.Since the COVID-19 pandemic began, people's lifestyles, especially sleep, have changed ${ }^{(15,16)}$.Lockdown measures were enforced "across the U K on 21 March 2020, arising from the evolving situation of COVID-19.In the most stringent lockdown circumstances, citizens of Scotland spent a total of 62 days", with it being relaxed to some degree on 23 May $2020^{(17)}$. A new survey by Sleep Criteria (Baglioni et al, 2020), entitled "Sleep Habits Post Quarantine in the US (2020)," aimed to investigate sleep habits both before and after pandemic-induced lockdown steps. The survey surveyed 1015 Americans around 18 and 79 years of age (55 percent female; 13.4 percent generation Z; 51.6 percent millennial; 9.9 percent baby boomer). Results of the survey would include: 53 percent suggested that they felt uncomfortable sleeping than before the pandemic, 67 percent believed that their sleep was better before the start of lockdown, 98 percent created new post-lockdown sleep problems and 68 percent experience stress or find it difficult to sleep, after the lockdown steps were removed ${ }^{(18)}$. Confronted with the Covid-19 outbreak, how has Iraq been responding since the government containment steps of March 16, 2020? How are attitudes, awareness and values affected by this ongoing health crisis? What effect on the community is psychological? Analysis aimed at tracking improvements in the general population's behavioral sleep (disorders) and their relative importance. In Iraq, one of the most common goals is to get proper sleep, not surprisingly. However there is a catch: our opportunity to get a decent night's sleep has been interrupted by the latest coronavirus pandemic. There's also a word for the some experts: " Covid-somnia ". This is the condition that affects others around the world whom live with Covid-19 suffering from stress-related insomnia. An August 2020 report by the University of Southampton in the UK found that the number of people with insomnia increased from one in six to one in four, with more difficulties sleeping in populations like mothers, critical staff and BAME groups (Women, displaced persons and members of minority Black, Asian or cultural groups) ( 19,20 ).In China, at the height of confinement, insomnia rates dropped from 14.6 percent to 20 percent. In Italy and Greece, a 'alarming distribution' of medical insomnia was seen, with approximately 40 per cent of those polled suffering from insomnia 
in a May study. In 2020, the term 'insomnia' was searched google more than ever. Many individuals are becoming insomniacs. Months of social distancing have shaken our everyday habits as the pandemic reaches its second year, blurred the boundaries among work and personal life, and introduced lasting confusion to their life - with dire implications for sleep. Because of it, our health and efficiency could face many difficulties. However, the scale of the issue could likely lead to improvements, incorporate new concepts in the way we interact with sleep problems and bring our life on track ${ }^{(21,22)}$.Social exclusion and lockout, since it gives most people more time at home, can be the saving grace of "COVID19", enabling flexibility in sleep-wake schedules and longer sleep period for others. (Fitbit,2020) just verified this when their global group recorded a shift in sleep habits. "They revealed that people are going to bed later and achieving more sleep than usual since the COVID-19 outbreak" (23) . They showed that after the COVID19 outbreak, citizens would go to bed later and get more sleep than usual. "Therefore, when individuals are denied more time to sleep, empirical research indicates that people seize this opportunity", suggesting that people in normal circumstances are in a state of poor sleep . The fact that sleep period has decreased in recent year's further supports $i^{(24)}$.

\section{DISCUSSION:}

It is hard to live with insomnia, whether or not associated with the pandemic. Constantly having trouble falling asleep or staying asleep may have long-term health impacts, including obesity, anxiety and depression.Sleep deprivation, put at much less than six hours a night by many health departments, also affects work efficiency ${ }^{(25)}$.Multiple studies have shown that sleep deprivation induces inattention and therefore a higher risk of making errors, affects focus, raises response times and influences our mood swings ${ }^{(26,27)}$.A survey published with $2250 \mathrm{UK}$ voters by King's College London (KCL) disclosed that 42 percent reported sleeping rather or less well than average until the nation was locked down (KCL, 2020). Consistent chronic stress during this extraordinary period is likely to give up health history, Consideration of the translational relation around sleep deprivation."The general population are likely to be experiencing higher than- normal stress levels".After all, almost half (57 percent) of participant becoming more "sad and stressed as a direct result of COVID-199", the KCL survey revealed (28) .Eventually, the authors also received initiatives to improve postquarantine sleep issues. Authors have found a regular sleep schedule and more exercise as their preferred solutions to increasing the quality of sleep ${ }^{(29.30)}$.Throughout the quarantine, though older generations were seen to have a more healthy sleep schedule, these generations were also less likely to do things such as exercise to promote sleep. Overall, quarter said that they are conscious of the standard of sleep and would aim to improve it after quarantine. In fact, color groups that have experienced a significant death toll from COVID-19 could be further at-risk for sleep behavior.

\section{CONCLUSION:}

This study concluded that the bulk of COVID-19 pandemicrelated sleep behavior research was on population health. Further comprehension of the possible changes in sleep behavior in the public and the effect on physical, social and physiological health, it is important that they are likely to be predominantly negative.

\section{REFERENCES}

[1] WHO (2020) COVID-19 and violence against women: What the health sector/system can do. Available at https://apps.who.int/iris/bitstream/handle/10665/331699/WHO-SRH-20.04eng.pdf

[2] Rundle AG, Park Y, Herbstman JB, et al. (2020) COVID-19 related school closings and risk of weight gain among children. Obesity 28(6): 1008-1009.

[3] Krueger JM, Frank MG, Wisor JP, Roy S. Sleep function: toward elucidating an enigma. SleepMed Rev. 2016;28:46-54. https://doi. org/10.1016/j.smrv.2015.08.005.

[4] Zaka A, Shamloo SE, Fiorente P, et al. (2020) COVID-19 pandemic as a watershed moment: A call for systematic psychological health care for frontline medical staff. Journal of Health Psychology 25(7): 883-887.

[5] Zhou J, Liu L, Xue P, et al. (2020) Mental health response to the COVID-19 outbreak in China. American Journal of Psychiatry. Epub ahead of print 7 May. DOI: 10.1176/appi.ajp.2020. 20030304.

[6] Majde JA, Krueger JM. Links between the innate immune system and sleep. J Allergy Clin Immunol. 2005;116(6):1188-98. https:// doi.org/10.1016/j.jaci.2005.08.005.

[7] Everson CA. Sustained sleep deprivation impairs host defense. Am J Phys. 1993;265(5 Pt 2):R1148-54. https://doi.org/10.1152/ ajpregu.1993.265.5.R1148.

[8] Patton AP, Hastings MH. The suprachiasmatic nucleus. Curr Biol: CB 2018;28(15):R816-22. https://doi.org/10.1016/j.cub.2018.06. 052.

[9] Pan X, Hussain MM. Clock is important for food and circadian regulation of macronutrient absorption in mice. J Lipid Res. 2009;50(9):1800-13. https://doi.org/10.1194/jlr.M900085- JLR200.

[10] National Records of Scotland (2020). Mid-year Population Estimates Scotland, Mid-2019. Available online at: https://www.nrscotland.gov.uk/files//statistics/ population-estimates/mid19/mid-year-pop-est-19-report.pdf (accessed August 8, 2020).

[11] Zachary Z, Brianna F, Brianna L, Garrett P, JadeW, Alyssa D, et al. Selfquarantine and weight gain related risk factors during the COVID-19 pandemic. Obes Res Clin Pract. 2020;14(3):210-6. https://doi.org/10.1016/j.orcp.2020.05.004.

[12] ParmetWE, SinhaMS. Covid-19 - the law and limits of quarantine. N Engl J Med. 2020;382(15):e28. https://doi.org/10.1056/ NEJMp2004211.

[13] Jansen EC, Prather A, Leung CW. Associations between sleep duration and dietary quality: results from a nationally-representative survey of US adults. Appetite. 2020;153:104748. https://doi.org/10. 1016/j.appet.2020.104748.

[14] Galli F, Reglero G, Bartolini D, Visioli F. Better prepare for the next one. Lifestyle lessons from the COVID-19 pandemic. Pharm Nutr. 2020;12:100193. https://doi.org/10.1016/j.phanu.2020. 100193.

[15] Ozamiz-Etxebarria, N., Mondragon, N. I., Santamaria, M. D., and Gorrotxategi, M. P. (2020). Psychological symptoms during the two stages of lockdown in response to the COVID-19 outbreak: an investigation in a sample of citizens in Northern Spain. Front. Psychol. 11:1491. doi: 10.3389/fpsyg.2020. 01491

[16] Alcohol Focus Scotland (2020). Scots Report Changing Drinking Patterns During Coronavirus Lockdown. Available online at: https://www.alcoholfocusscotland. org.uk/news/scots-report-changing-drinking-patternsduringcoronavirus- lockdown/ (accessed June 8, 2020).

[17] 17.Alcohol Change UK (2020). Drinking During Lockdown: Headline Finding. Available online at: https://alcoholchange.org.uk/blog/2020/covid19-drinkingduringlockdown-headline-findings (accessed June 8, 2020).

[18] 18. Baglioni, C., Spiegelhelder, K., Lombardo, C., and Riemann, D. (2020) "Sleep Habits Post Quarantine in the US". Sleep Med. Rev. 14, 227-238. doi: 10.1016/j. smrv.2020.10.007

This publication is licensed under Creative Commons Attribution CC BY 
[19] 19.Ingram J, Maciejewski G and Hand CJ (2020) Changes in Diet, Sleep, and Physical Activity Are Associated With Differences in Negative Mood During COVID-19 Lockdown. Front. Psychol. 11:588604. doi: 10.3389/fpsyg.2020.588604.

[20] 20.Alford, C., Martinkova, Z., Tiplady, B., Reece, R., and Verster, J. C. (2020). The effects of alcohol hangover on mood performance assessed at home. J. Clin. Med. 9:1068. doi: 10.3390/jcm9041068

[21] 21. Xiao, H., Zhang, Y., Kong, D., Li, S., and Yang, N. (2020). The effects of social support on sleep quality of medical staff treating patients with coronavirus disease 2019 (COVID-19) in January and February 2020 in China. Med. Sci. Monit. 26, e923549-1-e923549-8. doi: 10.12659/MSM.923549.

[22] 22.Wheaton, A. G., Chapman, D. P. and Croft, J. B. School Start Times, Sleep, Behavioral, Health, and Academic Outcomes: A Review of the Literature. J Sch Health, 2016, 86: 363-81.

[23] 23.Fitbit (2020) The impact of COVID-19 on global sleep patterns. Available at: https://blog.fitbit. com/covid-19-sleep-patterns/

[24] 24.Scheer FA, HiltonMF,Mantzoros CS, Shea SA. Adverse metabolic and cardiovascular consequences of circadian misalignment. Proc Natl Acad Sci U S A. 2009;106(11):4453-8. https://doi.org/ 10.1073/pnas.0808180106.

[25] 25.Simon C, Gronfier C, Schlienger JL, Brandenberger G. Circadian and ultradian variations of leptin in normal man under continuous enteral nutrition: relationship to sleep and body temperature. J Clin Endocrinol Metab. 1998;83(6):1893-9. https://doi.org/10.1210/ jcem.83.6.4864.

[26] 26.Huang Y and Zhao N (2020) Generalized anxiety disorder, depressive symptoms and sleep quality during COVID-19 outbreak in China: A webbased cross-sectional survey. Psychiatry Research 288: 112954
[27] 27.Mullington JM, Chan JL, Van Dongen HP, Szuba MP, Samaras J, Price $\mathrm{NJ}$, et al. Sleep loss reduces diurnal rhythm amplitude of leptin in healthy men. J Neuroendocrinol. 2003;15(9):851-4. https://doi.org/10.1046/j.13652826.2003.01069.x

[28] 28.KCL (2020) Life under lockdown: Coronvirus in the UK. Available at: https://www.kcl.ac.uk/news/ life-under-lockdown-coronavirus-in-the-uk

[29] 29.Xiao, H., Zhang, Y., Kong, D., Li, S. and Yang, N. Social Capital and Sleep Quality in Individuals Who Self-Isolated for 14 Days During the Coronavirus Disease 2019 (COVID-19) Outbreak in January 2020 in China. Med Sci Monit, 2020b, 26: e923921.

[30] 30. Nedeltcheva AV, Kilkus JM, Imperial J, Kasza K, Schoeller DA, Penev PD. Sleep curtailment is accompanied by increased intake of calories from snacks. Am J Clin Nutr. 2009;89(1):126-33. https:// doi.org/10.3945/ajcn.2008.26574

\section{AUTHORS}

First Author - Ahmed A.Hussein Al-Jumaily, Instructor,. C H $\mathrm{N}$, University of Mosul/College of Nursing"

Second Author - Nasir Muwfaq Younis, Assist.Prof,. C H N , University of Mosul/ College of Nursing", E-mail:

nasir.mufaq@uomosul.edu.iq

Third Author - Mahmoud Mohammed Ahmed, Instructor. C H $\mathrm{N}$, , University of Mosul/ College of Nursing". 